\title{
Correspondence
}

\section{When brain bullets met crowdfunding}

Stereotaxy - a surgical technique that uses a head clamp to pinpoint brain areas from coordinates of external landmarks and anatomical structures - was first applied in the nineteenth century, when it went largely unnoticed by the medical community. It was 'reinvented' 50 years later and is routinely used today, for example in deep-brain stimulation for diseases such as Parkinson's.

Gaston Contremoulins (1869-1950) was the selfeducated physicist who invented the 'metroradiographic' frame that marked the birth of stereotactic surgery (pictured). It was first used in 1897 to guide the removal of bullets from the brains of two young men who had survived after shooting themselves in the head.

This surgical triumph was crowdfunded following a public appeal by Contremoulins. It was reported in the French weekly newspaper l'Illustration and aroused great popular interest. In the scientific press, it attracted just a single report - in the proceedings of the French Academy of Sciences, Compte-rendus Hebdomadaires de l'Académie des Sciences.

Caroline Apra, Pierre Bourdillon, Marc Lévêque Pitié-Salpêtrière Hospital, Paris, France.

marc.leveque@aphp.fr

\section{IPBES disciplinary gaps still gaping}

The Intergovernmental Platform on Biodiversity and Ecosystem Services (IPBES) convenes this month to approve summaries for policymakers of the first assessments at its fourth plenary.

Despite early calls for IPBES to draw on a broader range of disciplines than did the Intergovernmental Panel on Climate Change (see E. Turnhout et al. Nature 488, 454-455; 2012), the social sciences and

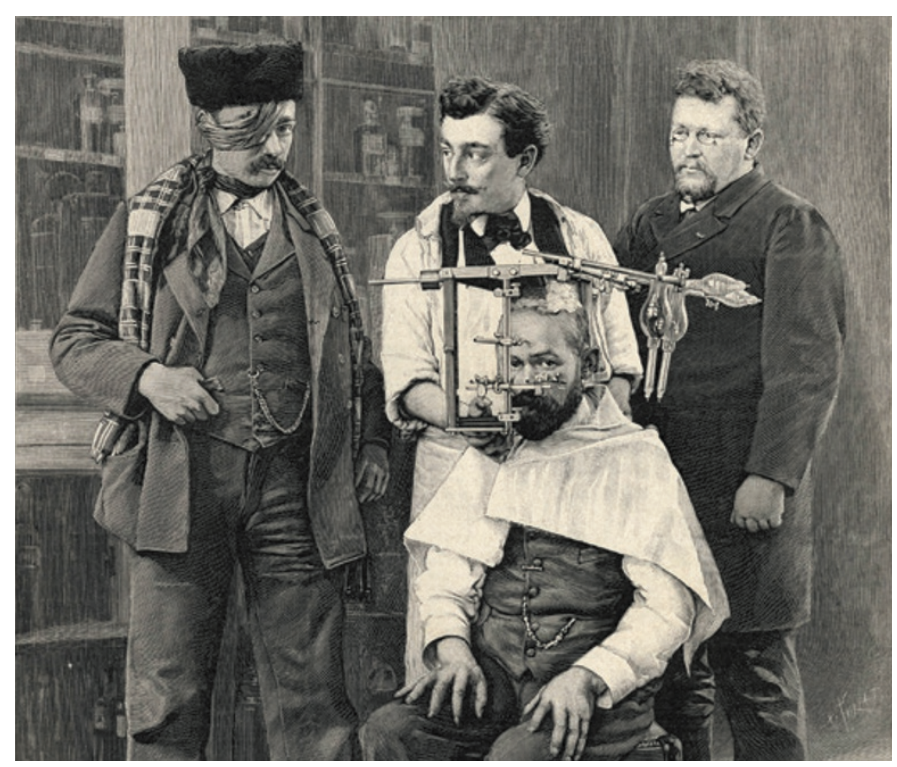

the humanities remain markedly under-represented. They make up less than $10 \%$ of the membership of IPBES expert groups, instead of the recommended $30 \%$. These disciplines should play a bigger part in IPBES assessments and in implementing the first IPBES work programme for 2014-18.

The imbalance mirrors institutional and knowledge barriers between research disciplines. The IPBES Secretariat and its Multidisciplinary Expert Panel need to consult more experts from the social sciences and humanities for nominations for assessments. The panel should encourage these stakeholders to engage in scoping and reviewing activities and to register on IPBES networking sites.

One of the IPBES objectives is to include experts with "balance in the terrestrial and marine natural sciences, social and economic sciences, and arts and humanities". The secretariat should review the disciplinary balance of all IPBES activities and products, and make the findings publicly available. Alice B. M. Vadrot University of Cambridge, UK.

Jens Jetzkowitz Philipps University Marburg, Germany. Lindsay C. Stringer University of Leeds, UK.

l.stringer@leeds.ac.uk

\section{More to fisheries than catch limits}

You suggest that the European Union is setting a worrying trend by ignoring scientific advice on overfishing, but that is only part of the story (Nature 528, 435; 2015).

The advice you mention refers to catch levels that are in line with the objectives of the EU Common Fisheries Policy. Those are based on the fish-stock biomass that can deliver maximum sustainable yields. Scientific advice on the annual catch limits (known as total allowable catches, or TACs) is aimed at delivering maximum sustainable yield and is provided by the International Council for the Exploration of the Sea (ICES). However, the TACs are set by the EU Council of Ministers and, as you point out, can sometimes exceed the levels advised by ICES.

Nevertheless, to accuse the EU of "ignoring" scientific advice in such cases oversimplifies the decision-making process. In fact, the extent to which TACs have exceeded the levels recommended by ICES has decreased since 2001, as you note.

Other objectives in the fisheries policy relate to their economic and social benefits. They aim to ensure the availability of food supplies and to contribute to a fair living standard for those who are dependent on fishing. Decisionmaking for fisheries management is therefore more complex than simply setting catch limits.

John Casey, Jann T. Martinsohn, Hendrik Dörner European Commission - JRC Institute for the Protection and Security of the Citizen, Ispra, Italy. john.casey@jrc.ec.europa.eu

\section{Metrics needed to track adaptation}

A lesser-known success of the Paris climate agreement in 2015 is the 'global adaptation goal', an ambitious plan for adapting to climate change that reaches beyond national boundaries. This is important because climate-change mitigation needs to take the world's adaptation potential into account.

To sustain the long-term goal of keeping the global average temperature rise well below $2{ }^{\circ} \mathrm{C}$, we also need evidence that the world can adapt to the impacts of warming. The Paris agreement aims to build a collective understanding of adaptation through metrics and tools that capture each country's efforts. Aggregating national contributions as a global trend will indicate whether humankind is on track to adapt.

The first step will be the agreement's ratification in April by at least 55 parties to the United Nations Framework Convention on Climate Change (UNFCCC) - which together account for at least $55 \%$ of total greenhouse-gas emissions.

It will next be necessary to define metrics that both reflect national circumstances and allow aggregation. To this end, scientists tracking adaptation will need to work with experts at the UNFCCC and organizations such as the UN Environment Programme.

Alexandre K. Magnan Institute for Sustainable Development and International Relations, Paris, France.

alexandre.magnan@iddri.org 